\title{
Resistant Starch from Mixed Flours (Banana, Jackfruit Seed and Job's Tear) and The Application in Food Product
}

\author{
Ratchanee Charoen ${ }^{1,}$, Sakaewan Tasana ${ }^{1}$, Wacharin Somprasong ${ }^{1}$, Sriwiang Rittisak ${ }^{1}$, and Wanticha Saveboworn ${ }^{2}$ \\ ${ }^{1}$ Department of Innovation and Product Development Technology, Faculty of Agro-Industry, King Mongkut's University of \\ Technology North Bangkok, Prachinburi, Thailand. \\ ${ }^{2}$ Department of Agro-Industry Technology and Management, Faculty of Agro-Industry, King Mongkut's University of Technology \\ North Bangkok, Prachinburi, Thailand.
}

\begin{abstract}
This research aimed to investigate resistant starch content and RVA property of three flours (Banana; BN, Jackfruit seed; JS and Job's tear; JT) with pre-treatment and dried under double drum dryer. Results showed that BN had the highest resistant starch content followed by JS and JT, respectively. The seven ratios of three flour mixtures from BN:JS:JT had been formulated using the mixture design. Results showed that the mixture containing BN:JS:JT ratio of 60:30:10 had the highest resistant starch content $(42.85 \%)$. Therefore, the waffle cones had been made with the flour mixture $(60: 30: 10)$ using a previously developed waffle cone recipe. The developed flour mixture could be able to replace wheat flour up to $30 \%$ of total flour according to the highest overall preference score. It was found that the final waffle cone recipe contained $9.96 \%$ and $54.60 \%$ of resistant and digestible starch, respectively. In conclusion, the developed flour mixture might be alternative flour for customers to reduce carbohydrate consumption and the nutritional enhancement of high resistant starch from banana, jackfruit seed and job's tear mixed flour in prototype food product.
\end{abstract}

\section{Introduction}

Resistant starch or indigestible starch is a type of starch that is incompletely digested by digestive enzymes in human small intestine, so its absorption is very limited. In terms of digestibility, resistant starch has similar properties to dietary fiber [1] that can be able to get through the small intestine into the large intestine at where microbes are able to digest and produce short chain fatty acids, which is beneficial for the growth of other gut microbes in the large intestine, promoting and maintaining a healthy gut $[2,3]$. The consistent consumption of dietary fibers and/or resistant starches may reduce the risk of diabetes, cardiovascular diseases and cancers $[4$, $5,6]$. Resistant starch could be found in nature and also obtained from chemical modification. In general, resistant starch can be classified into 5 groups: physically inaccessible starch, resistant granular starch, retrogradation starch, chemically modification starch and amylose-lipid complexed starch [7]. For example, in retrogradation starch, rearrangement of hydrogen-bonds among amylose molecules, is prepared from decreasing temperature of gelatinized starch. This phenomenon is known as retrogradation of starch forming stronger 3D network of starch that can prevent enzymatic degradation [7, 8]. Foods containing a high resistant starch content usually have low glycemic index (GI). Consumption of low GI foods such as beans, cereals, and vegetables can promote slow and consistent absorption of sugar into the bloodstream. This could help to manage blood sugar levels. In addition, several reports showed that it could suppress appetite, lower insulin levels, reduce fat and cholesterol levels $[9,10,11]$.

Recently, there were reports studying resistant starch obtained from various plants such as raw potatoes, unripe bananas, corn, mango, whole grains, legumes, rice [12, 13]. However, there had been limited information on applying resistant starches in actual food applications. Thus, the research aimed to formulate flour mixtures containing resistant starch made of banana, jackfruit seeds and job's tear, and to apply the developed flour mixtures in waffle cone recipe in order to replace wheat flour. The obtained flour mixture would be an alternative flour for customers concerning their health and wellness.

\section{Materials and Methods}

\subsection{Materials}

Hom Thong Banana (Musa Sapientum) from Prachinburi Local market (Prachinburi, Thailand) Jackfruit seed (Artocarpusheterophyllus L.) from Sookjai farm (Prachinburi, Thailand). Job's tear (Coixlacryma jobi Linn.) (Raitip, Thanya Farm Co., Ltd, Nonthaburi). Chemicals and reagents of analytical grade were obtained from Merck (Darmstadt, Germany) and Univar (USA Inc., USA). Resistant starch kit K-RSTAR 10/15 (Megazyme, Bray, Ireland).

\footnotetext{
* Corresponding author: ratchanee.c@agro.kmutnb.ac.th
} 


\subsection{Preparation of BN, JS and JT flours}

Banana peel was removed, and sliced to obtain $1 \mathrm{~cm}$ thickness (Slicer, Food equipment Co., Ltd, Thailand). Then, the sliced banana was blanching using stream at $70^{\circ} \mathrm{C}$ for $5 \mathrm{~min}$. Water was added and mixed to banana (100:130 wt/wt) using blender (Phillip HR2115, Thailand). The blended mixture was dried using a double drum dryer under the following conditions: $130 \pm 5^{\circ} \mathrm{C}$ drying temperature, $28.5 \mathrm{~mL} / \mathrm{min}$ feeding rate and 0.3 $\mathrm{mm}$ distance of double drum (CT drum dryer, DDD6L12-HT, Charoen TUT Co., LTD, Thailand). The final moisture was lower than $7 \%$. For Jackfruit seeds and Job's tear were boiled for $30 \mathrm{~min}$, mixed and blended with water (100:150 wt/wt) before dried under double drum dryer, then they were directly ground in a suitable grinder and passed through a 80 mesh sieve. The obtained banana, jackfruit seeds and job's tear flours were packed in LDPE bags and kept at $4^{\circ} \mathrm{C}$.

\subsection{Flour mixtures of BN:JS:JT}

The three-flour mixture was optimized using a mixture design. In mixture design, when there were three constraints on the component proportions. The constraints and lower-upper bound were consisted of banana flour (X1), jackfruit seed flour (X2), and job's tear flour (X3) ranged from $40-60 \%, 10-30 \%$, and $10-30 \%$, respectively. In general form of the constrained mixture problem was $\mathrm{X} 1+\mathrm{X} 2+\mathrm{X} 3=1$. Seven flour mixtures made of three materials were derived from a mixture design (Table 1). The physical and chemical properties of the influence on the response of each component can be obtained.

Table 1. Different flour mixed from BN, JS and JT obtained from a mixture design

\begin{tabular}{cccc}
\hline Formula & BN (\%) & JS (\%) & JT (\%) \\
\hline 1 & 60 & 30 & 10 \\
2 & 60 & 20 & 20 \\
3 & 60 & 10 & 30 \\
4 & 50 & 30 & 20 \\
5 & 50 & 20 & 30 \\
6 & 50 & 25 & 25 \\
7 & 40 & 30 & 30 \\
\hline
\end{tabular}

\subsection{Application of flour mixtures for waffle cone}

In this study, the developed flour mixtures were used in order to reduce wheat flour in the standard waffle cone recipe. The selected mixed flour from 2.3 was used to produce the waffle cone product prototype with replacing from $0-50 \%$ of all purpose flour. Placed egg whites $(220 \mathrm{~g})$, sugar (115 g), a whole milk (30 g) into the bowl and mixed together. Stirred in flour (100 g) and butter $(30 \mathrm{~g})$ until fully incorporated and batter was smooth, then poured and spreaded $45 \mathrm{~g}$ of batter over iron pan (6 inch) on low heat. Cooked for 5 min until the base had set, carefully rolled from the bottom of the cone to shape it suddenly. The prototype product was evaluated for $\% \mathrm{RS}$, digestible starch, proximate analysis, texture analysis and microbial test.

\subsection{Qualities analysis of flour, flour mixtures and waffle cone}

\subsubsection{Flour and flour mixtures}

Moisture content and $a_{w}$ of flours were determined according to the method of [14], $\mathrm{a}_{\mathrm{w}}$ was measured by a water activity meter under $25^{\circ} \mathrm{C}$ (Aqua Lab, Model. CX3TE, England). For $L^{*} a^{*} b^{*}$ color profiles of flours were measured using a colorimeter (Color Flex, Hunter lab, USA). The color differences of the samples were presented in terms of $\Delta \mathrm{E}$.

Water solubility: water solubility was determined using Anderson et al. [15] with some modified. Flour 1.0 $\mathrm{g}$ was heated in $20 \mathrm{~mL}$ distilled water at $60^{\circ} \mathrm{C}$ for $30 \mathrm{~min}$ without mixing. The sample was centrifuged at 2,200 rpm for $10 \mathrm{~min}$. Five milliliter of supernatant was separated, dried, weighted and calculated using equation below:

\section{$\%$ Solubility $=$ [weight of the soluble starch $(\mathrm{g}) /$ weight of the sample (g dry basis)] x100}

Pasting properties: The pasting temperature and paste viscosity characteristics of flour using a Rapid Visco Analyser (Newport Scientific model RVA-4, Perten Instrument, Huddinge, Sweden) following the AACC 61-02 method [16]. In brief, $3 \mathrm{~g}$ of flour and $25 \mathrm{~mL}$ of water were mixed in a canister and then subjected to a heat-hold-cool-hold temperature cycle that mimics cooking processing. The paste viscosity parameters expressed in rapid viscosity unit (RVU).

Resistant starch (RS) and digestible starch: The resistant starch content in flour was determined via the AOAC method (2007) using the RS Assay kit from Megazyme (K-RSTAR). The content expressed as \%RS sample weight (dry wt). $0.5 \mathrm{~g}$ fine powder was incubated in a shaking water bath with pancreatic $\alpha$-amylase and amyloglucosidase for $16 \mathrm{~h}$. An equal volume of ethanol was added to the digest and the RS was precipitated by centrifugation. The pellet was washed twice in $50 \% \mathrm{v} / \mathrm{v}$ $2 \mathrm{M}$ potassium hydroxide in and ice water bath with stirring, neutralized with acetate buffer and hydrolyzed to glucose with amyloglucosidase. The glucose was mixed with GOPOD reagent and measured at $510 \mathrm{~nm}$. (Spectrophotometer, Model Libra S32, Biochrom, England) against reagent blank. The \%RS and digestible starch was calculated by the formula given by the manufacturer (K-RSTAR 10/15, Megazyme, Bray, Ireland).

Amylose content: amylase content of flour was determined by colorimetric measurement of amylaseiodine complex [17]. Flour weighting $100 \mathrm{mg}$ was taken in boiling tube and mixed with $1 \mathrm{~mL}$ of ethanol. Then 9 $\mathrm{mL}$ of $1 \mathrm{~N}$ sodium hydroxide was added and the tubes were placed in boiling water bath for $10 \mathrm{~min}$. The volume was made up to $100 \mathrm{~mL}, 5 \mathrm{~mL}$ aliquot was taken and mixed with $1 \mathrm{~mL}$ of $1 \mathrm{~N}$ acetic acid $2 \mathrm{~mL}$ of iodine solution and kept in darkness for $20 \mathrm{~min}$. The volume was made to $100 \mathrm{~mL}$ with distilled water and measured the absorbance at $620 \mathrm{~nm}$. 


\subsubsection{Waffle cone product}

The proximate analysis (moisture, protein, fat, ash and fiber contents) of product prototype was done using the standard methods described in AOAC [18]. Protein contents of the sample was estimated from the determination of total nitrogen content by Kjeldahl method using a conversion factors of 6.25. Carbohydrate content was calculated by subtracting.

Texture analysis: Hardness and Crispiness of the sample was carried out using a texture analyzer (TA.XT plus, Stable Macro, England). The sample was compressed a cycle in TPA with a spherical probe (P-0.25) at a speed of $1.0 \mathrm{~mm} / \mathrm{s}$ until reaching $90 \%$ strain and post speed $10.0 \mathrm{~mm} / \mathrm{s}$. Compression data was recorded in newton of force. Fifteen replicates $(n=10)$ were performed for each treatment.

Microbial analysis: Total plate count (TPC) of product was analyzed. Briefly, the waffle cone $11 \mathrm{~g}$ was prepared by adding $99 \mathrm{~mL}$ of $0.1 \%$ peptone saline solution. Sample was homogenized for $2 \mathrm{~min}(400 \mathrm{rpm})$ at room temperature with stomacher (model 400 CIR, Seward, England). Subsequently decimal dilution series (10-fold) were prepared from the primary dilution using peptone solution and they were poured in plate count agar (PCA, HighMedia). The plates were incubated at $37^{\circ} \mathrm{C}(48 \mathrm{~h})$. The result was expressed as the number of colonyforming units (CFU) per gram of the sample.

\section{Results and Discussion.}

\subsection{Physical and chemical properties of flour.}

The obtained flours had the difference in appearances. According to color measurement (Table 2), BN had the highest lightness $\left(L^{*}\right)$, redness $\left(a^{*}\right)$, and yellowness $\left(\mathrm{b}^{*}\right)$ values in comparison with JS and JT flours $(\mathrm{P} \leq 0.05)$. It could be due to multiple factors such as natural pigments, different plant species, cultivation, and attention. According to Thai community product standard (2007), color characteristics of flours should be from their nature components. As illustrated in Fig. 1, the natural colors of BN JS and JT flours were pale yellow, pale brown and white cream, respectively.

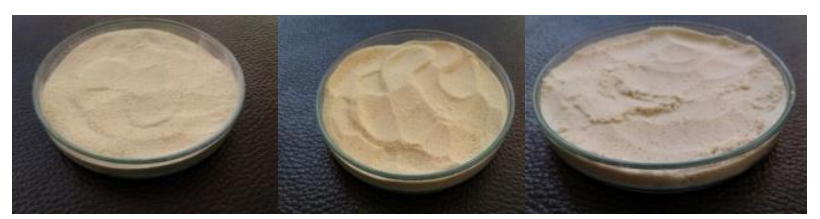

Fig. 1. The obtained flours after drum drying process. (A) BNflour, (B) JS-flour, (C) JT-flour.

As shown in Table 2, there were no significant differences among the solubilities of all three flours. It might be due to that all three flours had high amylose contents. Results showed that $\mathrm{BN}$ had higher amylose content than JS and JT flours. The obtained result was consistent with a previous report by [19] that the higher the high amylose content, the higher the crystallized part and the less solubility of starch as shown in table 2 .
Table 2. The properties of banana (BN), jackfruit seed (JS) and job's tear flours (JT).

\begin{tabular}{lccc}
\hline \multirow{2}{*}{ Color } & \multicolumn{3}{c}{ Flour } \\
\cline { 2 - 4 } & BN & JS & JT \\
\hline Physical properties & & & \\
$L^{*}$ & $68.64 \pm 0.18^{\mathrm{c}}$ & $77.67 \pm 0.27^{\mathrm{a}}$ & $72.95 \pm 0.62^{\mathrm{b}}$ \\
$a^{*}$ & $3.75 \pm 0.65^{\mathrm{a}}$ & $0.15 \pm 0.03^{\mathrm{b}}$ & $0.71 \pm 0.08^{\mathrm{b}}$ \\
$b^{*}$ & $16.74 \pm 0.21^{\mathrm{a}}$ & $16.54 \pm 0.58^{\mathrm{a}}$ & $10.92 \pm 0.04^{\mathrm{b}}$ \\
$\quad$ Solubility [\%] ${ }^{\mathrm{ns}}$ & $4.81 \pm 0.07$ & $4.74 \pm 0.29$ & $5.41 \pm 0.50$ \\
Chemical properties & & \\
Moisture [\%] & $3.11 \pm 0.13^{\mathrm{b}}$ & $3.51 \pm 0.15^{\mathrm{a}}$ & $3.79 \pm 0.19^{\mathrm{a}}$ \\
$\mathrm{a}_{\mathrm{w}}$ & $0.20 \pm 0.01^{\mathrm{b}}$ & $0.24 \pm 0.01^{\mathrm{a}}$ & $0.24 \pm 0.02^{\mathrm{a}}$ \\
Resistant starch [\%] & $32.24 \pm 2.89^{\mathrm{a}}$ & $27.03 \pm 0.18^{\mathrm{a}}$ & $3.05 \pm 0.71^{\mathrm{b}}$ \\
Digestible starch [\%] & $14.42 \pm 1.68^{\mathrm{b}}$ & $14.80 \pm 0.18^{\mathrm{b}}$ & $35.59 \pm 0.0^{\mathrm{a}}$ \\
Amylose content [\%] & $38.24 \pm 1.01^{\mathrm{a}}$ & $26.01 \pm 2.03^{\mathrm{b}}$ & $20.51 \pm 0.0^{\mathrm{c}}$ \\
\hline
\end{tabular}

Mean with different superscript letters in the same row are significantly different $(\mathrm{P} \leq 0.05)$, ${ }^{\text {ns }}$ means there is no statistically significant difference within the same row $(\mathrm{P} \leq 0.05)$

For chemical properties of three flours showed that moisture contents among the samples were statistically different $(\mathrm{P} \leq 0.05)$. JT contained the highest moisture content followed by JS and BN flours, respectively. Overall, the moisture contents $(<5 \%)$ of all flours were compiled with Thai community product standard (TISI). 1375/2550 [20]. Overall water activity (aw) of all samples ranged from $0.20-0.24$. There were significant differences of resistant starch contents among flour samples. BN contained the highest level of resistant starch in comparison with JS and JT flours. However, the observed resistant starch contents were different from a previous report $[19,21]$ that the resistant starch contents in banana, jackfruit seed and job's tear flours were $50-55 \%, 20-30 \%$, and $6-10 \%$, respectively. Furthermore, digestible starch contents of three flours were significant different $(\mathrm{P} \leq 0.05)$. It was well-known that resistant starch, partially hydrolyzed by digestive enzymes in the small intestine, can be digested by indigenous microbes in the large intestine. Gut microbes can be able converted resistant starch to short chain fatty acids similar to what microbes convert dietary fibers to short chain fatty acids $[22,13]$.

Amylose contents observed in all samples were significant different $(\mathrm{P} \leq 0.05)$. The levels of amylose in all flour samples ranged from $20.51-38.24 \%$. It was noted that BN had the highest amylose content (38.24\%). According to a previous report by Boonkong [19], they reported that the amylose contents in banana (Kluai Hom thong), jackfruit seed, and job's tear flours were $44.66 \%$, $26.01 \%$, and $20.51 \%$, respectively. Difference in amylose contents could be varied among the study due to different raw materials. Regarding to the relationship between amylose and resistant starch, there have been reported that a flour containing high amylose content have also high resistant starch content [19, 23, 24], which was consistent with a previous report by Buranachokpaisan [25] that a positive relationship between amylose and resistant starch was observed.

Pasting properties of flours were given in Fig. 2 and wheat flour had the highest final viscosity followed by $\mathrm{BN}$, JT and JS flours, respectively. At the beginning of heating process, JT was quickly increased in viscosity, however, after reached the maximum point at $1 \mathrm{~min}$, the viscosity was decreased unlit the end of the profile. In 
addition, the viscosity of the paste made from JS flour was not changed during the test condition. It should be noted that pasting profiles were strongly dependent on amylose and amylopectin in the raw materials. In general, for example, flours exhibiting the final viscosity higher than the peak viscosity pattern as a result of the amylose higher than amylopectin. When this type of starch was added into a product, usually increasing hardness of a product [6]. In comparison with wheat flour, it had the levels of amylopectin higher than amylose indicating by the observed the final viscosity lower than peak viscosity in RVA analysis.

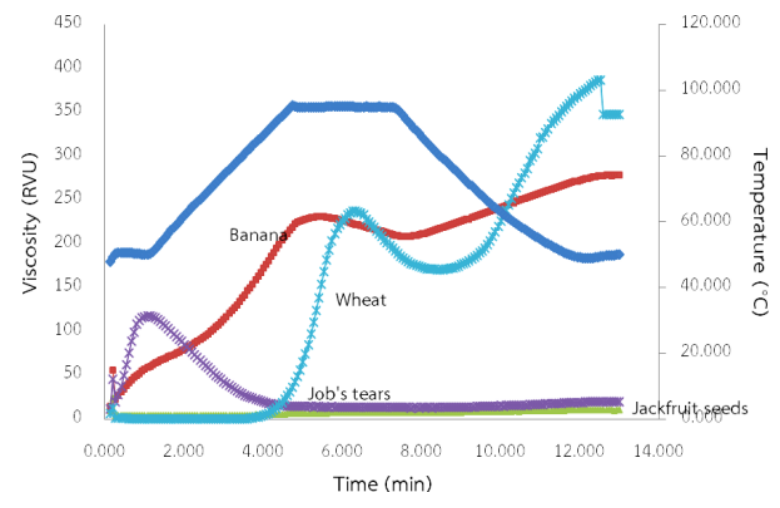

Fig. 2. Pasting properties obtained from wheat, banana, jackfruit seed and job's tear flours.

\subsection{Physical and chemical properties of mixed flour}

Table 3 showed physical properties of the seven flour mixtures according to a mixture design. Results indicated that different mixtures had different color appearances $(\mathrm{P} \leq 0.05)$ dependent on the original raw material colors. However, it was noted that the solubilities of 7 mixtures were not statistically different due to the tested flours containing high amylose content, which was consistent with a previous research $[13,7]$. They suggested that high amylose starch had low solubility due to its crystallization structure. In terms of chemical properties, the moisture content, water activity and amylose content of seven flour mixtures were significant different $(\mathrm{P} \leq 0.05)$ as illustrated in Table 4. According to Thai community product standard [20], all developed flours were compiled, at which the moisture content of the product is suggested at $12 \%$. It should be noted that differences in water activity $\left(\mathrm{a}_{\mathrm{w}}\right)$ and amylose content observed in the flour mixtures were dependent on the original observed values in banana, jackfruit seed and job's tear flours.

For pasting properties (Fig. 3), results indicated that the mixture with BF:JS:JT (60:30:10) exhibited the highest peak (197.41) and final viscosity values (244.72) followed by that the mixture with BF:JS:JT (60:20:20) that exhibited the highest peak (129.42) and final viscosity values $(82.58)$ besides these two mixtures. It was noted that other flour mixtures exhibited relatively low peak and final viscosity values. In comparison with wheat flour, the peak and final viscosity values of wheat flour were higher than the developed flour mixtures. It could be due to that wheat flour contains high ratio of amylopectin to amylose.

Table 3. Physical properties of the flour mixtures.

\begin{tabular}{ccccc}
\hline \multirow{2}{*}{$\begin{array}{c}\text { Treatment } \\
\text { BN:JS:JT }\end{array}$} & \multicolumn{4}{c}{ Color } \\
\cline { 2 - 5 } & $\boldsymbol{L}^{*}$ & $\boldsymbol{a}^{*}$ & $\boldsymbol{b}^{*}$ & $\begin{array}{c}\text { Solubility } \\
(\%)^{\text {ns }}\end{array}$ \\
\hline $60: 30: 10$ & $70.83 \pm 0.23^{\mathrm{de}}$ & $2.47 \pm 0.01^{\mathrm{b}}$ & $16.43 \pm 0.80^{\mathrm{a}}$ & $4.76 \pm 0.15$ \\
$60: 20: 20$ & $72.84 \pm 0.16^{\mathrm{a}}$ & $0.60 \pm 0.02^{\mathrm{f}}$ & $16.70 \pm 0.01^{\mathrm{a}}$ & $4.81 \pm 0.07$ \\
$60: 10: 30$ & $72.25 \pm 0.07^{\mathrm{b}}$ & $1.23 \pm 0.02^{\mathrm{e}}$ & $16.70 \pm 0.17^{\mathrm{a}}$ & $4.96 \pm 0.04$ \\
$50: 30: 20$ & $70.85 \pm 0.17^{\mathrm{de}}$ & $2.32 \pm 0.03^{\mathrm{c}}$ & $16.36 \pm 0.04^{\mathrm{a}}$ & $5.01 \pm 0.12$ \\
$50: 20: 30$ & $71.31 \pm 0.27^{\mathrm{c}}$ & $1.77 \pm 0.07^{\mathrm{d}}$ & $16.48 \pm 0.10^{\mathrm{a}}$ & $5.36 \pm 0.70$ \\
$50: 25: 25$ & $70.55 \pm 0.16^{\mathrm{e}}$ & $2.50 \pm 0.12^{\mathrm{b}}$ & $16.25 \pm 0.35^{\mathrm{a}}$ & $5.32 \pm 0.57$ \\
$40: 30: 30$ & $70.95 \pm 0.17^{\mathrm{d}}$ & $2.75 \pm 0.03^{\mathrm{a}}$ & $15.03 \pm 0.64^{\mathrm{b}}$ & $5.01 \pm 0.11$ \\
\hline
\end{tabular}

Mean with different superscript letters in the same columm are significantly different $(\mathrm{P} \leq 0.05),{ }^{\mathrm{ns}}$ means there is no statistically significant difference within the same columm $(\mathrm{P} \leq 0.05)$

Table 4. Chemical properties of the flour mixtures.

\begin{tabular}{cccc}
\hline $\begin{array}{c}\text { Treatment } \\
\text { BN:JS:JT }\end{array}$ & $\begin{array}{c}\text { Amylose } \\
\text { content [\%] }\end{array}$ & \%RS & $\begin{array}{c}\text { Digestible } \\
\text { starch }\end{array}$ \\
\hline $60: 30: 10$ & $36.52 \pm 2.23^{\mathrm{a}}$ & $42.85 \pm 2.89^{\mathrm{a}}$ & $29.91 \pm 0.62^{\mathrm{a}}$ \\
$60: 20: 20$ & $29.90 \pm 1.42^{\mathrm{b}}$ & $28.82 \pm 1.32^{\mathrm{b}}$ & $15.05 \pm 2.74^{\mathrm{c}}$ \\
$60: 10: 30$ & $26.87 \pm 3.35^{\mathrm{bc}}$ & $18.69 \pm 1.50^{\mathrm{c}}$ & $22.98 \pm 1.26^{\mathrm{b}}$ \\
$50: 30: 20$ & $24.50 \pm 0.01^{\mathrm{c}}$ & $12.56 \pm 0.54^{\mathrm{d}}$ & $18.14 \pm 1.95^{\mathrm{c}}$ \\
$50: 20: 30$ & $24.36 \pm 0.82^{\mathrm{c}}$ & $15.80 \pm 0.73^{\mathrm{cd}}$ & $22.79 \pm 0.70^{\mathrm{b}}$ \\
$50: 25: 25$ & $17.95 \pm 0.20^{\mathrm{d}}$ & $15.80 \pm 0.12^{\text {cd }}$ & $32.31 \pm 0.52^{\mathrm{a}}$ \\
$40: 30: 30$ & $7.74 \pm 0.09^{\mathrm{e}}$ & $11.61 \pm 3.11^{\mathrm{d}}$ & $32.05 \pm 1.18^{\mathrm{a}}$ \\
\hline
\end{tabular}

Mean with different superscript letters in the same columm are significantly different $(\mathrm{P} \leq 0.05)$

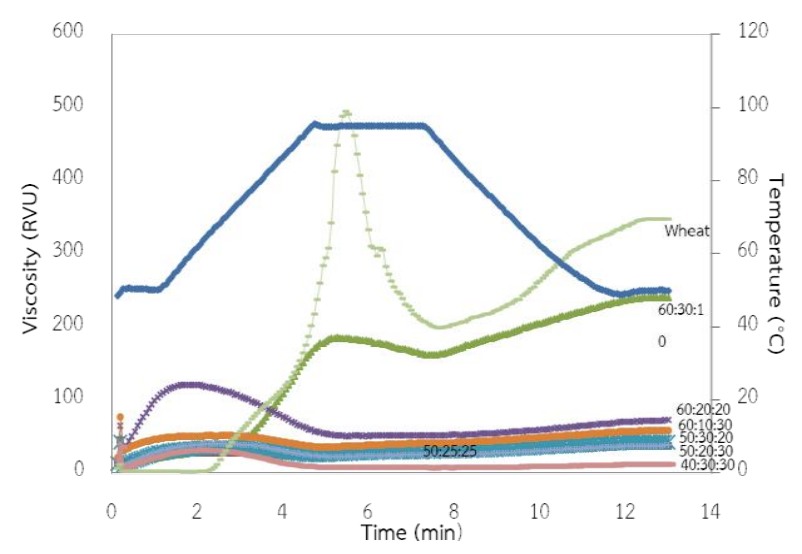

Fig. 3. Pasting properties obtained from different flour mixtures.

\subsection{Application of mixed flour for waffle cone product}

As shown in Fig. 4, waffle cone was made from the combination between the flour mixture (60:30:10) with $30 \%$ of wheat flour replacement. Table 5 showed physiochemical, texture and total microbial count of the final developed waffle cone. Result showed that $L^{*}, a^{*}$ and $b^{*}$ values of the waffle cone were $67.02,4.08$, and 25.58, respectively. Crispiness and hardness of the product were 729.24 and 1.04 , respectively. Total protein, total fat, ash, total fiber, total carbohydrate, and moisture content of the product were $12.92 \%, 13.73 \%$, $1.05 \%, 1.92 \%, 66.86 \%$, and $3.36 \%$, respectively. The final waffle cone product contained resistant starch content at $9.96 \%$, while digestible starch content was $54.60 \%$. For microbiological analysis, total microbial 
count was less than $30 \mathrm{CFU}$, which was complied with Thai community product standard [20] regulating at lower than $1 \times 10^{4} \mathrm{CFU} /$ gram sample in the final product.

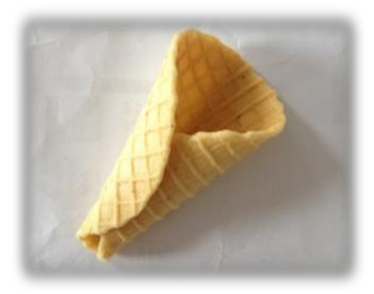

Fig. 4. The developed waffle cone.

Table 5. Physicochemical, texture and microbial properties of the developed waffle cone.

\begin{tabular}{lc}
\hline \multicolumn{1}{c}{ Parameter } & Value \\
\hline Physical & \\
$L^{*}$ (lightness) & $67.02 \pm 1.58$ \\
$a^{*}$ (redness) & $4.08 \pm 0.76$ \\
$b^{*}$ (yellowness) & $25.58 \pm 1.46$ \\
Crispiness [N] & $729 \pm 24.29$ \\
Hardness [N] & $1.04 \pm 0.53$ \\
\hline Chemical & $3.36 \pm 1.30$ \\
Moisture content [\%] & $0.31 \pm 0.02$ \\
a $_{\mathrm{w}}$ & $12.92 \pm 1.39$ \\
Protein content [\%] & $13.73 \pm 0.02$ \\
Total fat content [\%] & $1.05 \pm 0.06$ \\
Ash content [\%] & $1.92 \pm 0.05$ \\
Total fiber content [\%] & $66.86 \pm 0.06$ \\
Total carbohydrate content [\%] & $9.96 \pm 0.39$ \\
Resistant starch content [\%] & $54.60 \pm 2.60$ \\
Digestible starch content [\%] & \\
\hline Microbial & $<30$ \\
Total microbial count [CFU/gram] & \\
\hline
\end{tabular}

\section{Conclusion}

This research utilized the agricultural and waste products from banana, jackfruit's seed and job's tear for preparation of Resistant starch (RS). The contents of RS varied depending on the types of raw materials (banana>jackfruit's seed $>$ job's tear). Seven mixed flours accordance with the mixture design in the ratio of 60:30:10 (banana:jackfruit's seed:job's tear) affected the $\% \mathrm{RS}$ and pasting properties. The $\% \mathrm{RS}$ of mixed flour formular at 60:30:10 had highest value. For the final viscosity of pasting properties was closest to wheat flour. The mixed flour (60:30:10) was applied in replaced to wheat flour with $30 \%$ content of waffle cone recipe. Waffle cone prototype product had higher $\% \mathrm{RS}$ $(9.96 \%)$ and digestible starch $(54.60 \%)$. The further study of this research is storage stability study and consumer acceptance study.

The authors would like to express their appreciation to the Faculty of Agro-industry, King Mongkut's University of Technology North Bangkok for giving all facilities support. The authors thank Dr. Atikorn Panya, National Center for Genetic Engineering and Biotechnology; a member of NSTDA for good guidance in this study.

\section{References}

1. J.L. Buttriss, C.S. Stokes, Nutr Bull 33, 186-200 (2008)

2. N.H. Mermelstein, Food Tech. 4, 80-84 (2009)

3. A. Sharma, B.S.a Yadav, L. Ritika, Food Rev Int 24, 193-234. (2008)

4. R.N. Tharanathan, Crit Rev Biotechnol. 22 (1), 65-84 (2002)

5. J. Stavin, Nutr Res Rev. 17, 99-110 (2004)

6. S. Tongta, Research report SUT3-305-51-24-08. Suranaree University of Technology. (2008)

7. T. Sanz, A. Salvador, R. Baizauli, S.M. Fiszman, Eur. Food Res Technol. 229(2), 197-204 (2009)

8. D. Charalampopoulos, R. Wang, S.S Randlella, C. Webb, Int J Food Microbiol. 79, 131-141 (2002)

9. K.M. Behall, J. Hallfrisch, Eur J Clin Nutr. 56, 913920 (2002)

10. M.A. Brown, L.H. Storlien, I.L. Brown, Br. J Nutr 90, 823-827 (2003)

11. M.J. Keenan, J. Zhou, K.L. Mccutcheon, A.M. Raggio, H.G. Bateman, E. Todd, Obesity. 14, 15231534 (2006)

12. K.I. Baghurst, P.A. Baghurst, S.J. Record, G.A. Spiller (Ed.). Handbook of dietary fibre in human health (pp. 583-591), Boca Raton, FL; CRC Press. (2001)

13. M.G. Sajilata, R.S. Singhal, Carbohydr Polym. 59, 131-151 (2005)

14. AOAC., Official Method of Analysis. (International $17^{\text {th }}$ ed. Williams, S) Association of Official Analytical Chemists, Arilington, Virginia. (2000).

15. R.A. Anderson, H.F. Conway, V.F. Pfeifer, E.L. Griffin, Cereal Sci. Today. 14, 4-12 (1969)

16. AACC., American (Association of Cereal Chemists, AACC-International approved method of analysis, 11 ed. St. Paul. MN. (2000)

17. B.O. Juliano, Cereal Sci Today 16, 334-340 (1971)

18. Thai community products standards. Thai Industrial Standards Institute (TISI). 118/2555. (2012)

19. J. Boonkong, T. Bunmee, P. Ruenkeaw, J Food Sci Technol. 10(1), 19-29 (2015)

20. Thai community products standards. Thai Industrial Standards Institute (TISI). 1375/2550. (2007)

21. D. Narklaor, A. Sangnark, K. Limroongreungrat,. Burapha Sci J. 16(1), 12-21 (2011)

22. A.P. Nugent, Nutr Bull. 30, 27-54 (2005)

23. A.S. Alejandro, G.S. Sonia, V.T. Apolonio,. T. Juscelino, E.A. Tania, A.B. Luis, J Food Compos Anal. 20, 175-181 (2007)

24. F.M. Nunes, E.S. Lopes, A.S.P. Moreira, J. Simoes,. Carbohydr Polym. 141, 253-262 (2016)

25. K. Buranachokpaisan, K. Srinual, Research in Food Sci. Technol, Faculty of Science and Technology. Petchabun Rajabhat University. (2013) 